\title{
Determinants of chronic obstructive pulmonary disease severity in the late-elderly differ from those in younger patients
}

\author{
Mizuha Haraguchi ${ }^{1}$, Hidetoshi Nakamura ${ }^{1,2^{*}}$, Mamoru Sasaki ${ }^{1}$, Masaki Miyazaki ${ }^{1}$, Shotaro Chubachi ${ }^{1}$, \\ Saeko Takahashi ${ }^{1}$, Koichiro Asano ${ }^{3}$, Paul W. Jones ${ }^{4}$, Tomoko Betsuyaku ${ }^{1}$ and the Keio COPD Comorbidity \\ Research (K-CCR) Group
}

\begin{abstract}
Background: Although the age range of chronic obstructive pulmonary disease (COPD) patients is broad, few studies have focused on the effects of age on disease characteristics.

Methods: Keio University and affiliated hospitals established an observational COPD cohort. Patients were assessed using high resolution computed tomography (CT) to quantify emphysema, health status using the COPD assessment test (CAT) and the St. George's Respiratory Questionnaire (SGRQ), spirometry, echocardiogram, dual X-ray absorption of bone, biomarkers and comorbid diagnoses. We examined the characteristics of COPD patients aged 75 and over compared with patients below 75 .

Results: A total of 443 patients comprising 252 patients aged $<75$ years and 191 patients aged $\geq 75$ years, were enrolled. Emphysematous changes on CT and prevalence of possible pulmonary hypertension were greater in lateelderly patients. The slope of the relationship between CT emphysema densitometry score and forced expiratory volume in $1 \mathrm{~s}$ was significantly less steep in the late-elderly than the younger patients $(p=0.002)$. CAT and total SGRQ scores and the frequency of long-term oxygen therapy were significantly higher in the late-elderly with moderate airflow obstruction compared to those of the younger in the same grade, although the opposite was seen in lateelderly patients with very severe airflow obstruction. Hypertension, aortic aneurysm, prostatic hypertrophy, anemia, and cataract are more prevalent in late-elderly patients.
\end{abstract}

Conclusions: Elderly COPD patients show a varied age-related pattern of disease that warrants specific attention in clinical practice above and beyond assessment of airflow limitation.

Trial registration Clinical trial registered with the University Hospital Medical Information Network (UMIN000003470, April 10, 2010)

Keywords: Chronic obstructive pulmonary disease, Comorbidity, Elderly, Symptom, Emphysema

\section{Background}

Chronic obstructive pulmonary disease (COPD), one of the most prevalent health conditions, is the fourth leading cause of death worldwide [1]. COPD morbidity and mortality have been increasing in many countries, in part

\footnotetext{
*Correspondence: htnakam@nifty.com

${ }^{2}$ Department of Respiratory Medicine, Saitama Medical University, 38 Morohongo, Moroyama-machi, Iruma-gun, Saitama 350-0495, Japan Full list of author information is available at the end of the article
}

due to an aging population world-wide [2]. By the mid21st century, the chance of living beyond 60 years will be $98 \%$ in Japan/Oceania, $82 \%$ in Western Europe, and $69 \%$ in China [3]. Relative to the 2011 world population, recent United Nations projections estimate that by 2100 the number of people aged $>60$ years will triple, with an eightfold increase in those $>80$ [1]. However, although increases in life expectancy and the size of the elderly population during the past several decades might explain 
the current increase in COPD, the relationship may be more complex, including factors such as differential susceptibility to tobacco, anatomic and systemic differences, behavioral differences, and differences in response to available therapeutic modalities.

Japan is a super-aged society, ranked first in the world. The late elderly (aged $\geq 75$ years) accounted for $11.6 \%$ of Japan's population in the 2010 national population census. In recent years pulmonary and primary care physicians in Japan have been more ready to diagnose and treat COPD patients of advanced age, and although it is known that COPD currently mostly affects middle-aged and elderly people, few studies have focused on how the features of COPD differ by age.

In the past, COPD severity was simply classified based upon the \% forced expiratory volume in $1 \mathrm{~s}\left(\mathrm{FEV}_{1}\right)$, because it was believed that the majority of patients followed a path of disease progression in which the severity of the disease tracked the severity of the airflow limitation [4]. However, it has become clear in recent years that comprehensive assessment requires more than $\mathrm{FEV}_{1}$ measurement. The Global Initiative for Chronic Obstructive Lung Disease (GOLD) has proposed an assessment for COPD treatment based on the patient's level of symptoms and future risk of exacerbation, in addition to the severity of spirometric abnormality [5].

Very elderly patients with COPD may present differently from younger ones; they may have a different pattern of comorbidities, and a different survival rate after acute exacerbations. Physicians may also have an age bias that may affect both diagnosis and treatment. The purpose of this study was thus to examine the characteristics of COPD patients aged 75 and over compared with those aged below 75 .

\section{Methods}

\section{Study populations}

Keio University and affiliated hospitals have established an observational COPD cohort, registered with the University Hospital Medical Information Network (UMIN000003470), for investigations of the management of COPD comorbidities [6]. All patients were clinically stable without exacerbations for at least 1 month prior to study. The protocol was approved by the Ethics Committees of Keio University on July 29, 2009 (No. 20090008) and the affiliated hospitals, and written informed consent was obtained from each patient.

\section{Measurement of pulmonary functions}

All participants underwent spirometry when in a stable condition during the baseline examination, according to ATS protocols using an electronic spirometer [7]. Predicted values were derived from the guidelines for pulmonary function tests issued by the Japanese Respiratory Society [8]. The classification of disease severity was based on GOLD spirometric grading [2], Grade I: mild $\left(\mathrm{FEV}_{1}\right.$ /forced vital capacity $(\mathrm{FVC})<0.70, \% \mathrm{FEV}_{1} \geq 80 \%$ ), Grade II: moderate $\left(\mathrm{FEV}_{1} / \mathrm{FVC}<0.70, \% \mathrm{FEV}_{1} 50-80 \%\right)$, Grade III: severe $\left(\mathrm{FEV}_{1} / \mathrm{FVC}<0.70, \% \mathrm{FEV}_{1} 30-50 \%\right)$ and Grade IV: very severe COPD $\left(\mathrm{FEV}_{1} / \mathrm{FVC}<0.70, \% \mathrm{FEV}_{1}\right.$ $<30 \%)$.

\section{Assessment of clinical parameters}

At enrollment, a full medical and smoking history and current pharmacological treatment were obtained and clinical examinations were performed. Comorbid diagnoses were established using clinical history and examination findings, supported by a review of available medical records. The Hospital Anxiety and Depression Scale (HADS) was used, with a cut-off score of 11 points each for a probable status of anxiety or depression [9]. Gastro-esophageal reflux disease (GERD) symptoms were evaluated using a self-reported Frequency Scale for the Symptoms of GERD (FSSG) questionnaire, consisting of 12 items, with a cut-off score of 8 points for GERD [10].

\section{Questionnaires on health-related quality of life (QOL)}

Each patient's health-related QOL was evaluated using three questionnaires. Two were disease-specific: the COPD Assessment Test (CAT) and St George's Respiratory Questionnaire (SGRQ) [11-14]. The CAT has been validated in Japan using the same population enrolled in the present study [6]. The Medical Outcomes Study Short-Form 36-Item (SF-36) version 2 was also used to measure the patients' general health status $[15,16]$, and it was reported that COPD patients have SF-36 lower scores, representing worse health-related QOL [17]. All of the questionnaires were completed by the patients themselves, at home, in the stable state.

\section{Evaluation of emphysema on CT scan}

Quantitative High Resolution computed tomography (HRCT) analyses of emphysema were performed. Lowattenuation areas (LAAs) using a threshold level of -950 HU were determined using a Discovery CT 750HD CT system (GE Healthcare, Tokyo), adjusting the threshold on each model of CT scan using a CT scanner test object, the Multipurpose Chest Phantom N1 "Lungman" (Kyoto Kagaku, Kyoto, Japan) [18] and calculated its percentage relative to the entire lung area (LAA\%) using the workstation Lexus $64^{\circledR}$ (AZE Ltd., Tokyo) [19].

\section{Echocardiographic evaluation}

Echocardiograms were obtained using two commercially available echocardiography systems (GE Vivid7/Vivid9, 
GE Healthcare, Horten, Norway and iE33/Sonos7500, Philips; Amsterdam, Netherlands). A $2.5-\mathrm{MHz}$ transducer was used to obtain the images in the parasternal and apical views, corresponding to the standard long-axis, and two-chamber and four-chamber images, respectively. Standard two-dimensional and color Doppler data were collected. The estimated systolic pulmonary artery pressure (eSPAP) was calculated [20], and pulmonary arterial hypertension was defined by an eSPAP $\geq 35 \mathrm{mmHg}$ [21].

\section{Statistical analysis}

All data are expressed as mean, unless otherwise stated. Student's $t$ test was performed to compare mean values between the two groups. Comparisons of data among the four patient groups were performed using analysis of variance (ANOVA), followed by a Tukey-Kramer post hoc analysis. Comorbidities were included as a categorical variable. A $\chi^{2}$ analysis was conducted to compare the frequencies between two groups. Relationships between quantitative data were examined using Spearman tests. Analysis of covariance (ANCOVA) were conducted to examine whether the slope of the relationship between two parameters differed between the patients aged $<75$ and $\geq 75$ years. $P$ values less than 0.05 were considered significant. All data were analyzed using the JMP version 9.0.2 software for Windows.

\section{Results}

\section{Demographic measures}

The mean age of the 443 COPD patients was $72.6 \pm 8.2$ SD years (range $43-91$ years), and $92 \%$ were males. The clinical characteristics of the subgroups of late-elderly patients (aged $\geq 75$ years) and relatively younger patients (aged $<75$ years) are tabulated (Table 1). There was no significant difference between the two subgroups in smoking amount, BMI, proportion of the GOLD grades, and their treatment with medication. Current smokers were more prevalent in the younger patients.

Numbers, mean (SD), and median (range) of age in GOLD grades I to IV were as follows; I: $\mathrm{n}=93,71.6$ (8.2), 73 (49-89), II: $\mathrm{n}=202,72.9$ (8.6), 73 (43-91), III: $\mathrm{n}=115,72.9$ (7.7), 74 (51-89), IV: $\mathrm{n}=33,72.3$ (7.9), 74 (54-89). There was no significant difference in age among the GOLD grades.

\section{Vital capacity (VC) and FEV ${ }_{1}$ by GOLD grade}

An individual's $\mathrm{VC}$ and $\mathrm{FEV}_{1}$ are expected to fall with increasing age, premised on the repeated findings that respiratory function worsens with age. In GOLD grades I-III, the $\mathrm{VC}$ and $\mathrm{FEV}_{1}$ values were significantly lower in the late-elderly patients compared to the younger patients, but among the GOLD grade IV patients there
Table 1 Demographic data of the COPD patients $(n=443)$

\begin{tabular}{llll}
\hline & Age $<\mathbf{7 5}$ years & Age $\geq \mathbf{7 5}$ years & $\boldsymbol{p}$ value \\
\hline No. of subjects & 252 & 191 & \\
Age (mean, years) & 66.9 & 80.0 & \\
Sex (male/female) & $231 / 21$ & $175 / 16$ & n.s. \\
Smoking amount (mean, & 56.9 & 55.6 & n.s. \\
$\quad$ pack-year) & & & \\
Current smoker (\%) & 17.3 & 7.7 & 0.004 \\
BMI (mean, kg/m²) & 22.5 & 22.3 & n.s. \\
VC (mean, ml) & 3365 & 2934 & $<0.001$ \\
VC (mean, \% predicted) & 93.8 & 93.5 & n.s. \\
FEV (mean, ml) & 1717 & 1465 & $<0.001$ \\
FEV (mean, \% predicted) & 60.5 & 62.1 & n.s. \\
GOLD grade (I/I/llI/IV) & $52 / 114 / 67 / 19$ & $41 / 88 / 48 / 14$ & n.s. \\
LTOT (\%) & 10.7 & 15.9 & n.s. \\
CAT (mean) & 12.5 & 12.7 & n.s. \\
SGRQ symptom (mean) & 36.5 & 37.9 & n.s. \\
SGRQ activity (mean) & 39.7 & 47.5 & 0.001 \\
SGRQ impact (mean) & 18.3 & 22.3 & 0.04 \\
SGRQ total (mean) & 27.4 & 32.2 & 0.02 \\
Oral corticosteroids (\%) & 3.2 & 3.6 & n.s. \\
Inhaled corticosteroids (\%) & 35.0 & 32.8 & n.s. \\
Long-acting $\beta 2$ agonists (\%) & 42.0 & 48.8 & n.s. \\
Long-acting muscarinic & 64.0 & 58.3 & n.s. \\
antagonists (\%) & & & \\
\hline BMIbody mass index, VCvial & & \\
\hline
\end{tabular}

$B M I$ body mass index, $V C$ vital capacity, $F E V$, forced expiratory volume in $1 \mathrm{~s}$, GOLD Global Initiative for Obstructive Lung Disease, LTOT long-term oxygen therapy, CAT COPD assessment test, SGRQ St George's Respiratory Questionnaire, n.s. not significant

was no difference between the two groups (Fig. 1a, c). In contrast, the mean $\mathrm{VC} \%$ predicted and $\mathrm{FEV}_{1} \%$ predicted were not lower in the late-elderly patients compared to the younger patients when grouped by GOLD grade (Fig. 1b, d).

\section{Age-related difference in the relationship} between emphysema on CT scan and FEV

CT scans were performed on 246 patients enrolled at Keio University Hospital. Overall, there was a significant correlation between the degree of emphysema and $\% \mathrm{FEV}_{1}(\mathrm{r}=-0.453, \mathrm{p}<0.0001)$, but in the patients aged $<75$ years, the slope of the relationship between these two variables was significantly steeper than in patients aged $>75$ (ANCOVA, $p=0.002$ ) (Fig. 2).

\section{Age-related difference in the prevalence of pulmonary hypertension}

Echocardiography was performed on 265 patients enrolled at Keio University Hospital, and the eSPAP was measurable for 179 of these patients (72.8\%). Among the GOLD grade II patients, the prevalence of possible 

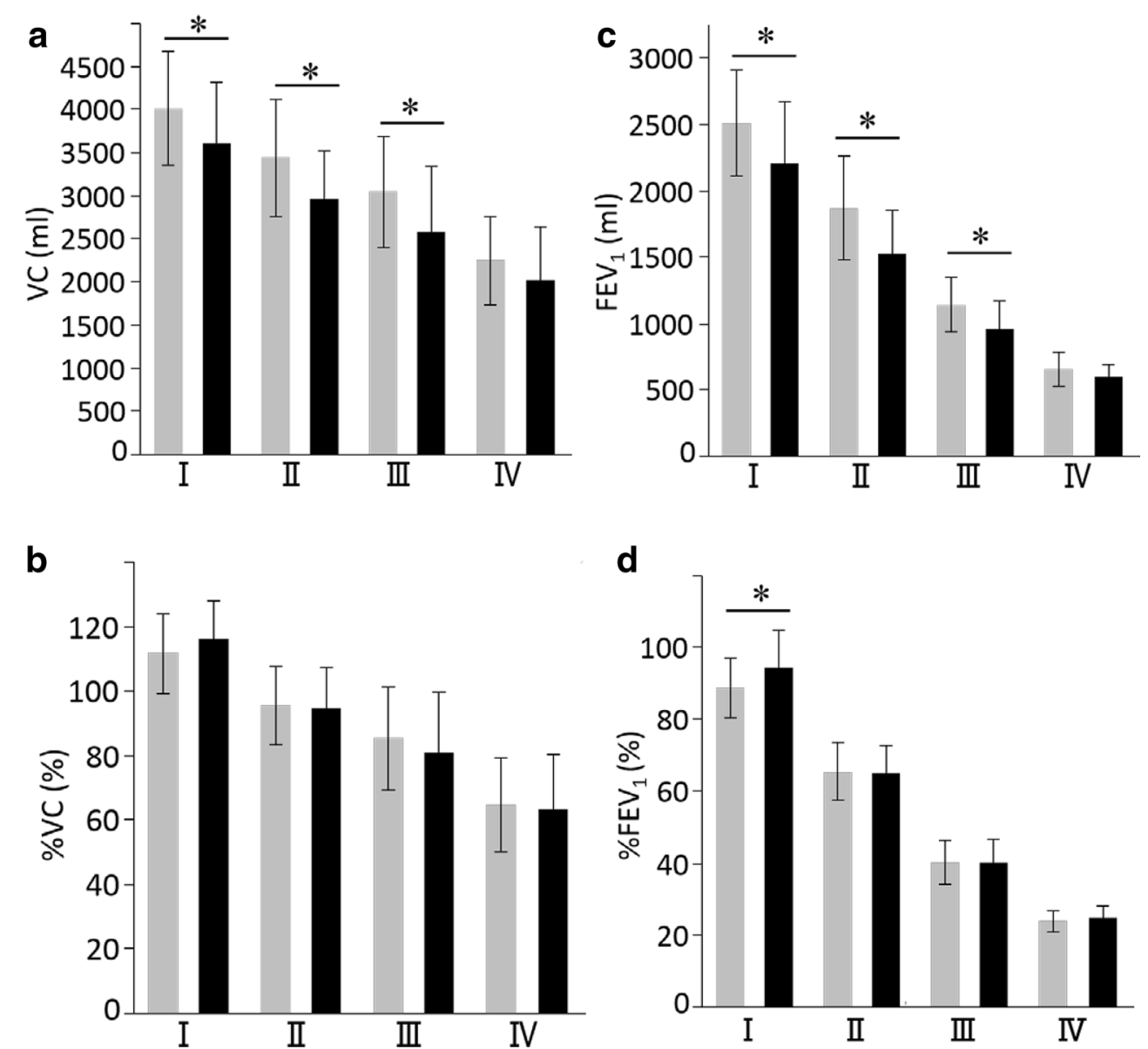

Fig. 1 Comparisons of $\mathrm{VC}$ and $\mathrm{FEV}_{1}$ values between COPD patients aged $<75$ and $\geq 75$ years with different grades of COPD. a VC, b $\% \mathrm{VC}, \mathbf{c} F E V_{1}, \mathbf{d}$ $\% \mathrm{FEV}_{1}$. Gray columns $<75$ years old, Black columns $\geq 75$ years old. Data are presented as mean \pm standard deviation (SD). ${ }^{*} \mathrm{p}<0.05$

pulmonary hypertension was significantly higher in the late-elderly patients compared to the younger patients. (28.2 vs. $7.5 \%, p=0.02$ ) (Fig. 3a). After controlling for differences in LAA \% between the two groups of patients, patients $\geq 75$ years had a higher level of eSPAP (31.9 vs. $27.1 \mathrm{mmHg}, p=0.001$ ) (Fig. 3b).

\section{Age-related difference in health-related QOL}

The CAT score increased (worsened) with worsening GOLD grade in the younger COPD patients $(p<0.0001)$; this was largely due to the very high score in the younger patients in GOLD Grade IV. There was no overall significant difference in CAT score between GOLD grades in the late-elderly COPD patients $(p=0.15)$ (Fig. 4). Differences between elderly and younger patients were inconsistent across the GOLD grades. The same pattern seen with the CAT were also seen in with SGRQ scores (compare Fig. 4 with Fig. 5), and with the generic questionnaire, the SF-36 (Additional file 1: Figure S1, Additional file 2: Figure S2).

\section{Age-related variability in the introduction of long-term} oxygen therapy (LTOT)

There was no significant difference in the ratio of patients receiving LTOT between the younger and late-elderly COPD patients as a whole (Table 1), although there was a pattern of more LTOT use in the late-elderly patients in GOLD Grades I-III, but significantly less in GOLD IV patients (Table 2), perhaps because of the combined mortality impact of age, severe airflow limitation and severe hypoxia.

\section{Differences in the frequency of comorbidities by age}

Some comorbidities including hypertension (46.5 vs. $29.6 \%, p<0.01$ ), aortic aneurysm (6.6 vs. $1.7 \%$, $p<0.05)$, prostatic hypertrophy (19.7 vs. $7.7 \%$, $p<0.01)$, anemia (37.2 vs. $15.7 \%, p<0.01)$, and cataract $(64.1$ vs. $34.8 \%, p<0.01)$ were significantly more prevalent in the late-elderly compared to the younger patients (Table 3 ). 

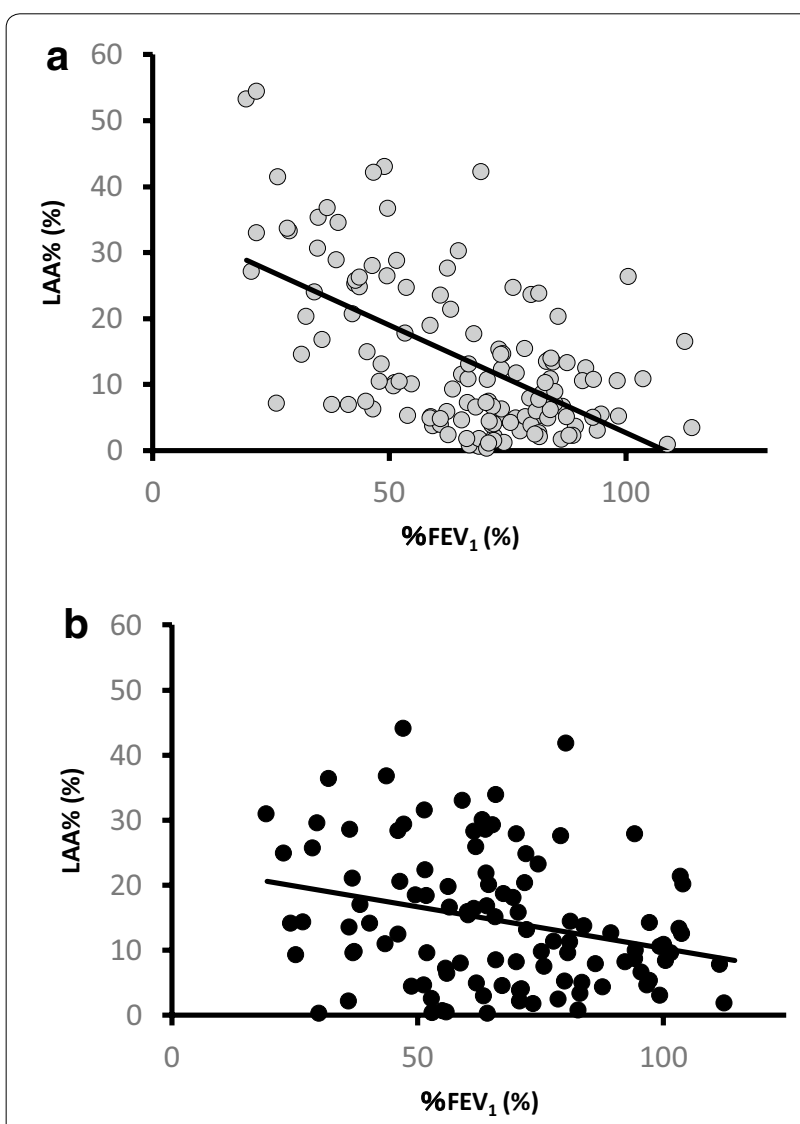

Fig. 2 Correlation between $\% \mathrm{FEV}_{1}$ and LAA \% in each age group. a Gray circles $<75$ years old, b black circles $\geq 75$ years old. ${ }^{*} p=0.002$ comparison of the slopes between two different age groups

\section{Discussion}

Japan became a super-aged society before other countries, but this trend is present in all developed and in developing countries [1]. The results of the present study suggest that COPD patients surviving to become late-elderly have a different pattern of lung function disturbance and emphysema to those who are younger. Although a strong correlation of emphysema on CT scan with spirometry was found in a large-scale cohort [22], the severity of emphysema varies widely even among patients with the same grade of COPD [19], our data suggests that age may be a factor in that variation. One of the problems in comparing different ages of COPD patients is the reliability of estimates of normal ranges for $\mathrm{FEV}_{1}$ in the late-elderly. $\mathrm{VC}$ and $\mathrm{FEV}_{1}$ are thought to decline linearly with age; this being the basis of equations for calculating predicted values based on age. In the present study, late-elderly COPD patients showed lower $\mathrm{VC}$ and $\mathrm{FEV}_{1}$ values compared to those in the younger patients, but they were classified in the same grade of COPD based on percentage of predicted values. These observations imply that $\mathrm{VC}$ and $\mathrm{FEV}_{1}$ were similarly reduced by age across the grades of airflow limitation in patients with COPD to those in the Japanese general population. The less steep slope of the relationship between emphysema and $\mathrm{FEV}_{1}$ shown in Fig. 2 may be due to a healthy survivor effect (late elderly patients with severe airflow limitation being more likely to die), but relationships between the severities of airflow limitation and emphysema can be different in the late-elderly and younger patients with COPD.

We compared health-related QOL using the CAT, SGRQ and SF-36 between the two groups at different levels of airflow limitation. Overall there was a weak but generally consistent trend towards patients with more severe airflow limitation having worse QOL. To the authors' best knowledge, no previous studies have focused on the age-related differences of health-related QOL in patients with COPD. Age negatively affects physical function, physical role limitations and general health [23] and our study reports similar findings, although we have shown that late-elderly patients in GOLD IV have better health status than younger patients. This may reflect a healthy survival effect, since the proportion of late elderly patients GOLD IV who were on LTOT was much lower than in the younger patients with the same degree of airflow limitation. This conclusion was supported by the data on pulmonary hypertension, since for any given degree of airflow limitation, the late-elderly patients were more likely to have pulmonary hypertension, except in GOLD IV. We have previously reported that comorbid diseases such as depression, anxiety, and GERD may increase CAT scores [3]. However, there was no difference in the prevalence of such comorbidities between the late-elderly and younger patients. In contrast age-related comorbid diseases including hypertension, aortic aneurysm, prostatic hypertrophy, anemia, and cataract were not associated with CAT scores in the present study (data not shown).

One of the strengths of our cohort study is that the study population is a community-living sample. The patients enrolled provide a representative range of the socio-economic characteristics of COPD patients in Japan, registered at a general clinical practice, a university hospital or a related facility. Coincidentally, other COPD cohort studies conducted in different Japanese locality investigated participants with a similar average age [24, 25]. Indeed, COPD patients in Japan are typically elderly, and there might be a "healthy survivor effect" in their late seventies and beyond. We speculate that these olderaged COPD cohorts contain a higher proportion of people who, for whatever reasons, did not experience such 


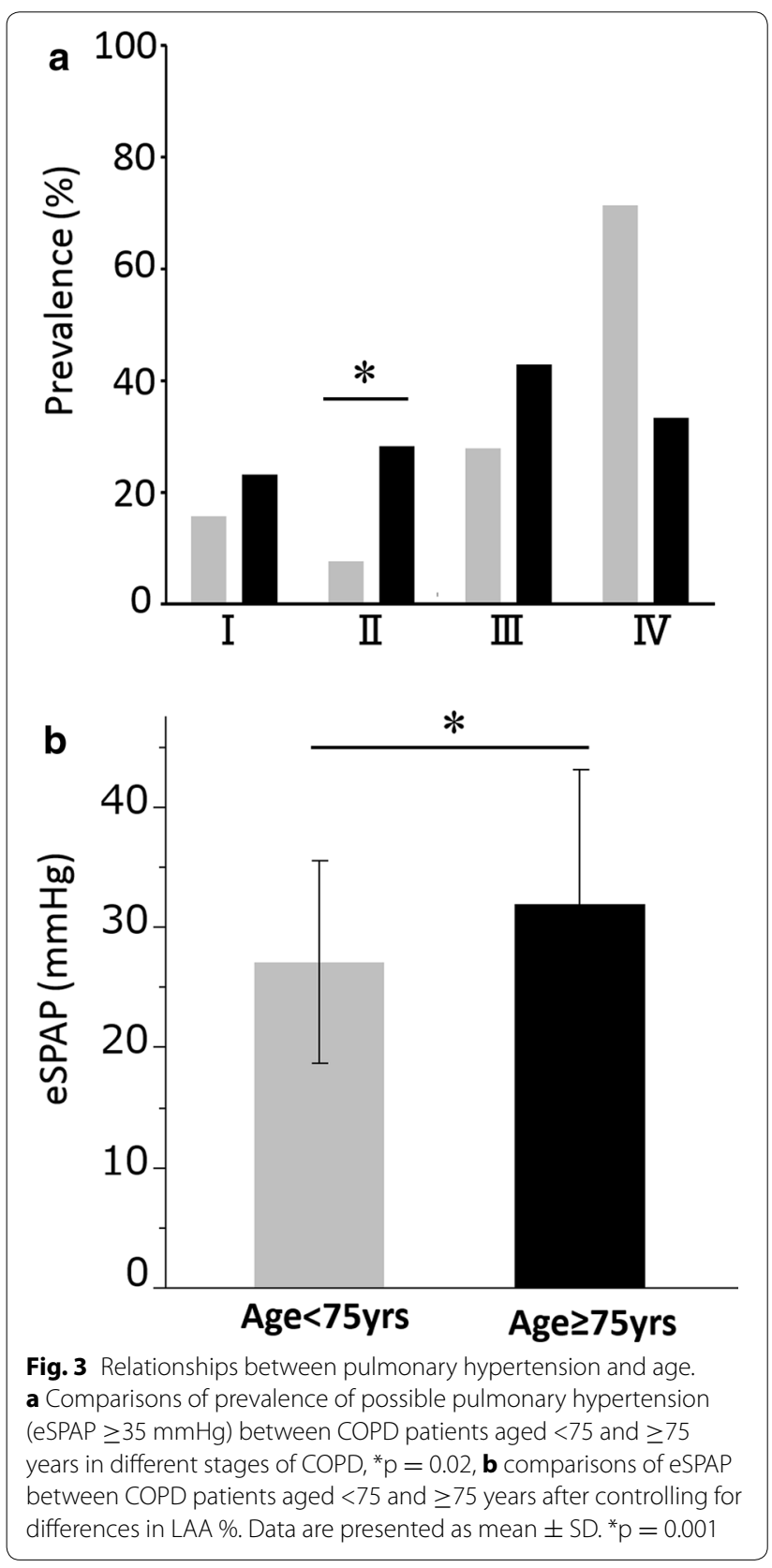

serious or life-threatening comorbid problems as their younger peers. We have no reason to believe that the pattern seen in these COPD patients is a particularly Japanese phenomenon.

As COPD is more prevalent at older ages, it represents an increasing problem for public healthcare worldwide. Few studies have reported the clinical features of COPD in very elderly patients [26, 27], and the need for more research into the impact of age on this growing

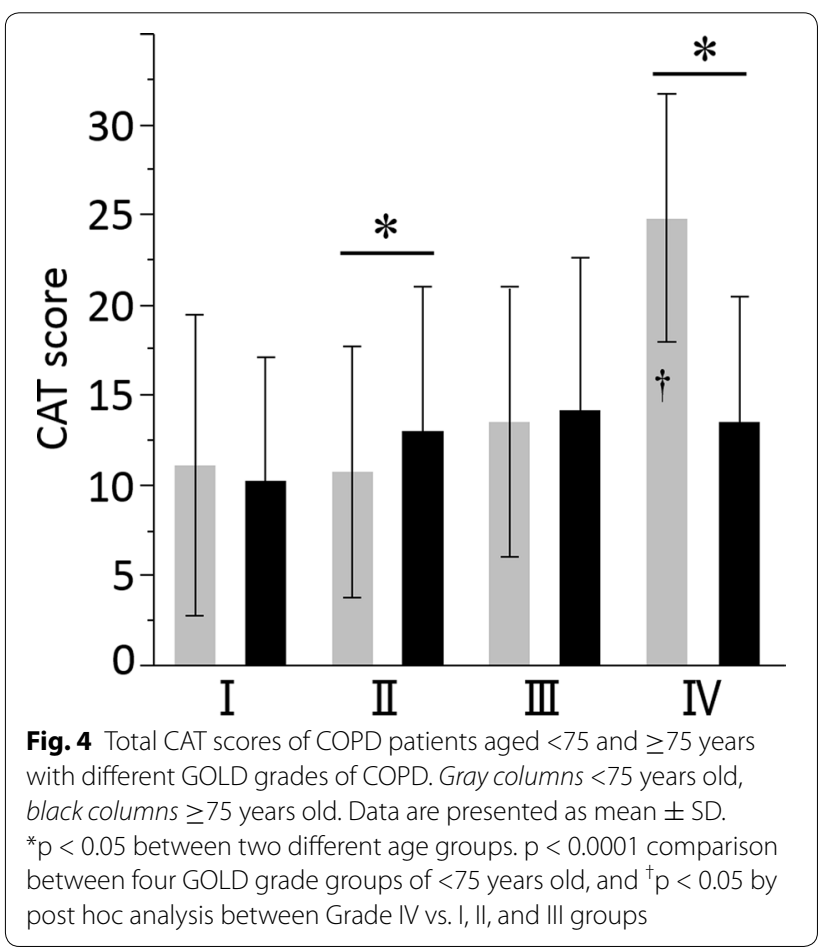

subpopulation of COPD patients is urgent [28]. Our study identified late-elderly COPD patients with moderate airflow limitation who manifested severe emphysema and/or pulmonary hypertension, and disabling dyspnea that were not usually complicating features of COPD patients with moderate airflow limitation for the younger patients. In part this may be because the conventional $\% \mathrm{FEV}_{1}$ staging scheme may be misleading as a measure of severity in late-elderly patients [29]. An alternative staging strategy that accounted for age-related changes in pulmonary function and variability in spirometric performance, i.e., the lambda-mu-sigma method, demonstrated that $28.1 \%$ of patients with severe COPD were classified as moderate using the standard GOLD grades [30].

One limitation of this study is the lack of age-matched healthy controls for comparison, although that is complicated by the fact that the elderly often live with one or more chronic conditions [31]. Another limitation is that the objective quantification of emphysema severity and pulmonary hypertension was not assessed for all of the enrolled subjects, because we had to use different types of CT scanners and echocardiography systems in each affiliated hospital. Finally, this study mainly consisted of male patients $(91.6 \%)$, and further investigations are necessary to test whether our observations are applicable to female COPD patients. 
a Symptom

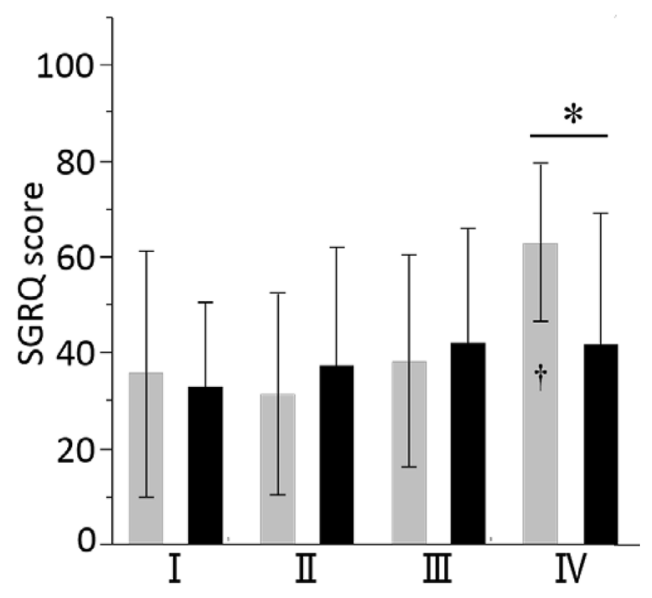

c Impact

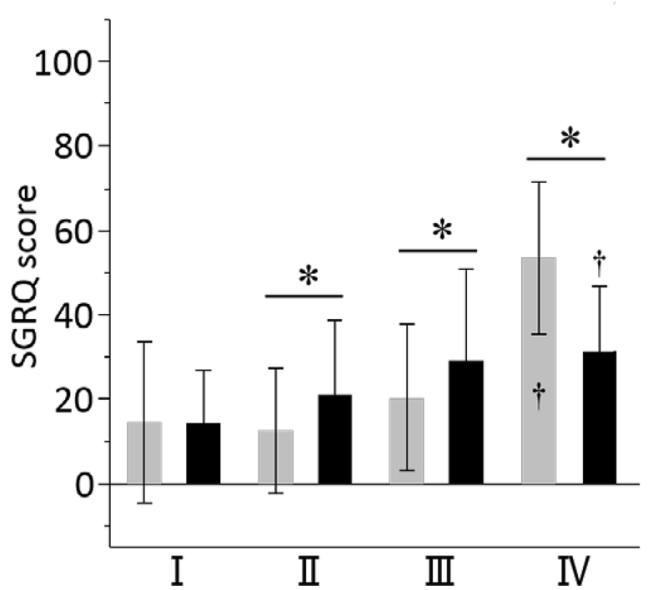

b Activity

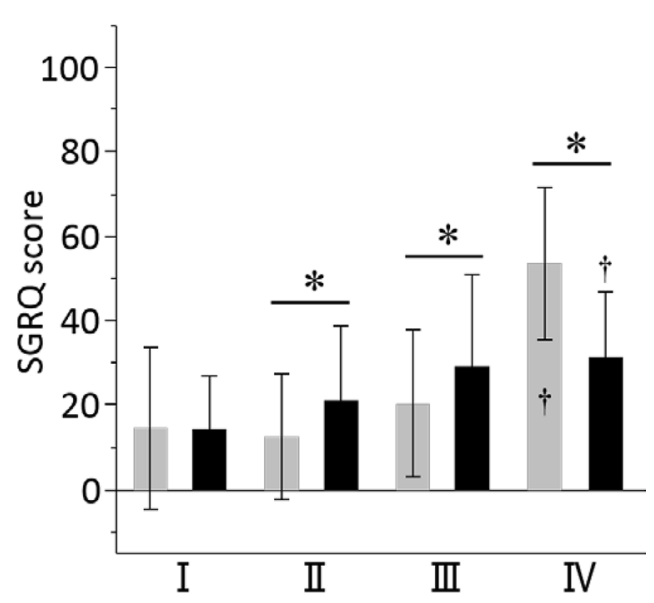

d Total

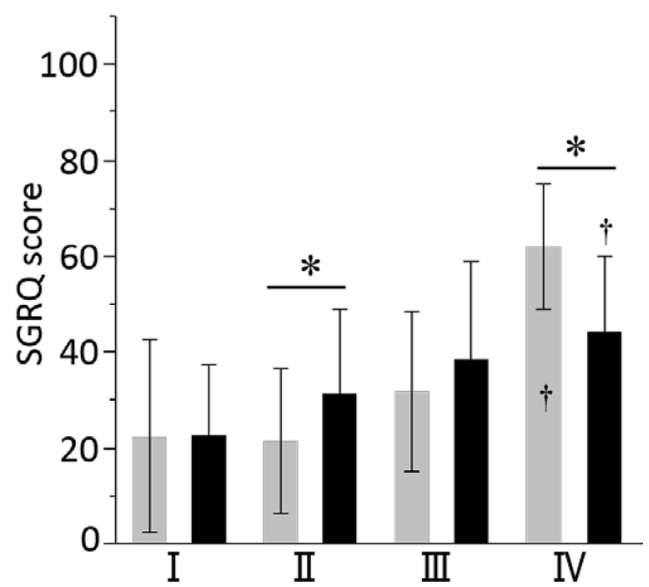

Fig. 5 Comparisons of SGRQ scores between COPD patients aged $<75$ and $\geq 75$ years in different grades of COPD. a Symptom scores, $\mathbf{b}$ activity scores, $\mathbf{c}$ impact scores, $\mathbf{d}$ total scores. Data are presented as mean \pm SD. ${ }^{*} p<0.05 . p<0.001$ comparison between four GOLD grade groups of $<75$ years old, and ${ }^{\dagger} p<0.05$ by post hoc analysis between Grade IV vs. I, II, and III groups (a-d). $p<0.001$ comparison between four GOLD grade groups of $\geq 75$ years old, and $+p<0.05$ by post hoc analysis between Grade IV vs. I and II groups $(\mathbf{b})$, Grade IV vs. I group (c, d)

Table 2 Prevalence of LTOT among COPD patients $<75$ and $\geq 75$ years old

\begin{tabular}{|c|c|c|c|}
\hline & \multicolumn{2}{|l|}{ Prevalence (\%) } & \multirow[t]{2}{*}{$p$ value } \\
\hline & $<75$ years old & $\geq 75$ years old & \\
\hline । & 1/52 (1.9\%) & $3 / 41(7.3 \%)$ & n.s. \\
\hline$\|$ & 4/114 (3.5\%) & 13/88 (14.8 \%) & 0.0043 \\
\hline III & 7/67 (10.4 \%) & 11/48 (22.9\%) & n.s. \\
\hline IV & 14/19 (73.7\%) & 2/14 (14.3\%) & 0.002 \\
\hline
\end{tabular}

n.s. not significant

\section{Conclusion}

The present study demonstrates that very elderly individuals present a different pattern of COPD than younger patients. This is possibly the result of different pathways of disease coupled with a healthy survivor effect. Assessments of COPD severity from a multidimensional perspective are essential for the appropriate attribution of symptoms and use of COPD-directed therapies. The results of the present study further strengthen the need for a better assessment of airflow limitation in late-elderly 
Table 3 Prevalence of comorbidities

\begin{tabular}{|c|c|c|c|c|}
\hline & \multicolumn{3}{|c|}{ Prevalence (\%) } & \multirow[t]{2}{*}{$p$ value } \\
\hline & $<75$ years & $\geq 75$ years & Total & \\
\hline Asthma & 21.1 & 23.0 & 22.0 & n.s. \\
\hline Interstitial pneumonia & 5.4 & 10.9 & 7.8 & n.s. \\
\hline Lung cancer & 5.2 & 6.0 & 5.5 & n.s. \\
\hline Other malignancies & 17.6 & 25.7 & 21.2 & 0.05 \\
\hline Anxiety & 8.3 & 5.6 & 7.1 & n.s. \\
\hline Depression & 7.9 & 13.5 & 10.2 & 0.07 \\
\hline Hypertension & 29.6 & 46.5 & 37.0 & $<0.01$ \\
\hline Coronary artery disease & 9.4 & 14.2 & 11.5 & n.s. \\
\hline Arrhythmia & 9.9 & 12.0 & 10.8 & n.s. \\
\hline Chronic heart failure & 4.3 & 8.2 & 6.0 & n.s. \\
\hline Aortic aneurysm & 1.7 & 6.6 & 3.9 & 0.01 \\
\hline Diabetes mellitus & 15.0 & 14.8 & 14.9 & n.s. \\
\hline Dyslipidemia & 17.6 & 15.9 & 16.8 & n.s. \\
\hline Hyperuricemia & 7.3 & 10.4 & 8.7 & n.s. \\
\hline Cerebral infarction & 5.2 & 7.7 & 6.3 & n.s. \\
\hline Chronic renal failure & 1.2 & 3.2 & 2.0 & n.s. \\
\hline $\begin{array}{l}\text { Gastro-esophageal reflux } \\
\text { disease }\end{array}$ & 34.9 & 31.1 & 33.3 & n.s. \\
\hline Peptic ulcer & 7.3 & 12.6 & 9.6 & 0.09 \\
\hline Chronic sinusitis & 12.8 & 8.8 & 11.1 & n.s. \\
\hline Prostatic hypertrophy & 7.7 & 19.7 & 13.0 & $<0.01$ \\
\hline Liver dysfunction/Liver cirrhosis & 8.7 & 8.8 & 8.7 & n.s. \\
\hline Collagen disease & 2.1 & 1.7 & 1.9 & n.s. \\
\hline Anemia & 15.7 & 37.2 & 25.0 & $<0.01$ \\
\hline Osteoporosis & 15.2 & 23.7 & 18.9 & 0.06 \\
\hline Cataract & 34.8 & 64.1 & 47.9 & $<0.01$ \\
\hline
\end{tabular}

n.s. not significant

patients than current $\mathrm{FEV}_{1}$ prediction values and lateelderly COPD patients warrant specific attention in clinical practice.

\section{Additional files}

Additional file: Fig. S1. Comparisons of SF-36 components between COPD patients aged $<75$ and $\geq 75$ years in different stages of COPD. Data are presented as mean \pm standard deviation (SD). ${ }^{*} p<0.05$. a: Vitality, b: Physical functioning, c: Bodily pain, d: General health perceptions.

Additional file: Fig. S2. Comparisons of SF-36 components between COPD patients aged $<75$ and $\geq 75$ years in different stages of COPD. Data are presented as mean \pm standard deviation (SD). ${ }^{*} p<0.05$. a: Physical role functioning, b: Emotional role functioning, c: Social role functioning, d: Mental health.

\section{Abbreviations}

K-CCR: Keio COPD Comorbidity Research; COPD: chronic obstructive pulmonary disease; CT: computed tomography; CAT: COPD assessment test; SGRQ: St. George's Respiratory Questionnaire; FEV $\mathrm{V}_{1}$ : forced expiratory volume in 1 s; UMIN: University Hospital Medical Information Network; GOLD: Global Initiative for Chronic Obstructive Lung Disease; FVC: forced vital capacity;
HADS: Hospital Anxiety and Depression Scale; GERD: gastro-esophageal reflux disease; FSSG: frequency scale for the symptoms of GERD; QOL: quality of life; SF-36: Medical Outcomes Study Short-Form 36-Item; HRCT: high resolution computed tomography; LAAs: low-attenuation areas; eSPAP: estimated systolic pulmonary artery pressure; ANOVA: analysis of variance; ANCOVA: analysis of covariance; LTOT: long-term oxygen therapy.

\section{Authors' contributions}

$\mathrm{MH}$ participated in the design of the study and performed the statistical analysis, and was a major contributor in writing the manuscript. HN planned the study design and contributed to the interpretation of the results. TB conceived of the study and participated in its design and coordination and helped to draft the manuscript. MS, MM, and SC contributed to the collection of data and interpretation of results. ST and KA conceived of the study and participated in its design and coordination. PWJ contributed to the data analysis, interpretation of data, and editing of the manuscript. All authors read and approved the final manuscript.

\section{Author details}

${ }^{1}$ Division of Pulmonary Medicine, Department of Medicine, Keio University School of Medicine, 35 Shinanomachi, Shinjuku-ku, Tokyo 160-8582, Japan. ${ }^{2}$ Department of Respiratory Medicine, Saitama Medical University, 38 Morohongo, Moroyama-machi, Iruma-gun, Saitama 350-0495, Japan. ${ }^{3}$ Division of Pulmonary Medicine, Department of Medicine, Tokai University School of Medicine, 143 Shimokasuya, Isehara, Kanagawa 259-1193, Japan. ${ }^{4}$ Division of Clinical Science, St. George's University of London, Cranmer Terrace, London SW17 ORE, UK.

\section{Acknowledgements}

We thank Chiyomi Uemura for her contribution to the collection of data. This study was funded by GlaxoSmithKline.

We also thank the following members for their participation in the Keio COPD Comorbidity Research (K-CCR) group: Hidefumi Koh (Saiseikai Utsunomiya Hospital), Fumio Sakamaki (Tokyo Saiseikai Central Hospital), Takeshi Terashima and Tatsu Matsuzaki (Department of Respiratory Medicine, Tokyo Dental College), Morio Nakamura and Keishi Tsuduki (Eiju General Hospital), Naoto Minematsu (Hino City Hospital), Koichi Sayama (Kawasaki City Hospital), Takashi Inoue (Sano Public Welfare General Hospital), Naoki Miyao (Nihon Kokan Hospital), Kazumi Nishio (Kawasaki City Ida Hospital), Hiroki Tateno (Saitama City Hospital), Yoshitaka Oyamada and Shuichi Yoshida (Tokyo Medical Center), Toru Shirahata (Saitama Medical Center), Akira Umeda (International Medical Welfare College Shioya Hospital).

\section{Competing interests}

TB discloses having received honoraria/paid expert testimony and her university having received research grants from GlaxoSmithKline. PWJ discloses that his university has received honoraria and research grants from GlaxoSmithKline. The other authors declare that they have no competing interests.

Received: 3 August 2015 Accepted: 16 December 2015

Published online: 04 January 2016

\section{References}

1. United Nations Department of Economic and Social Affairs Population Division. World population prospects: the 2010 revision, volume I Comprehensive Tables. 2011. http://esa.un.org/wpp/documentation/pdf/ WPP2010_Volume-I_Comprehensive-Tables.pdf. Accessed 22 July 2015.

2. Global Initiative for Chronic Obstructive Lung Disease (GOLD). Global Strategy for the Diagnosis, Management, and Prevention of Chronic Obstructive Pulmonary Disease. Updated 2015. http://www.goldcopd. org/uploads/users/files/GOLD_Report_2015.pdf. Accessed 22 July 2015.

3. Lutz W, Sanderson W, Scherbov S. The coming acceleration of global population ageing. Nature. 2008;451:716-9.

4. Tantucci C, Modina D. Lung function decline in COPD. Int J Chron Obstruct Pulmon Dis. 2012;7:95-9.

5. Vestbo J, Hurd SS, Agustí AG, Jones PW, Vogelmeier C, Anzueto A, et al. Global strategy for the diagnosis, management, and prevention of chronic obstructive pulmonary disease: GOLD executive summary. Am J Respir Crit Care Med. 2013;187:347-65. 
6. Miyazaki M, Nakamura H, Chubachi S, Sasaki M, Haraguchi M, Yoshida S, et al. Analysis of comorbid factors that increase the COPD assessment test scores. Respir Res. 2014;15:13.

7. The Committee on Proficiency Standards for Clinical Pulmonary Function Laboratories of American Thoracic Society. Standardization of Spirometry, 1994 Update. American Thoracic Society. Am J Respir Crit Care Med. 1995;152:1107-36.

8. Committee of Pulmonary Physiology, the Japanese Respiratory Society: The Japanese Respiratory Society Guidelines for pulmonary function tests: spirometry, flow-volume curve, diffusion capacity of the lung (in Japanese). Tokyo; 2004.

9. Zigmond AS, Snaith RP. The hospital anxiety and depression scale. Acta Psychiatr Scand. 1983;67:361-70.

10. Kusano M, Shimoyama Y, Sugimoto S, Kawamura O, Maeda M, Minashi $\mathrm{K}$, et al. Development and evaluation of FSSG: frequency scale for the symptoms of GERD. J Gastroenterol. 2004;39:888-91.

11. Jones PW, Harding G, Berry P, Wiklund I, Chen WH, Kline Leidy N. Development and first validation of the COPD Assessment Test. Eur Respir J. 2009;34:648-54.

12. Jones PW, Quirk FH, Baveystock CM, Littlejohns P. A self-complete measure of health status for chronic airflow limitation. The St. George's Respiratory Questionnaire. Am Rev Respir Dis. 1992;145:1321-7.

13. Hajiro T, Nishimura K, Tsukino M, Ikeda A, Koyama H, Izumi T. Comparison of discriminative properties among disease-specific questionnaires for measuring health-related quality of life in patients with chronic obstructive pulmonary disease. Am J Respir Crit Care Med. 1998;157:785-90.

14. Hajiro T, Nishimura K, Tsukino M, Ikeda A, Koyama H, Izumi T. Analysis of clinical methods used to evaluate dyspnea in patients with chronic obstructive pulmonary disease. Am J Respir Crit Care Med. 1998;158:1185-9.

15. Fukuhara S, Bito S, Green J, Hsiao A, Kurokawa K. Translation, adaptation, and validation of the SF-36 Health Survey for use in Japan. J Clin Epidemiol. 1998:51:1037-44.

16. Bentsen SB, Rokne B, Wahl AK. Comparison of health-related quality of life between patients with chronic obstructive pulmonary disease and the general population. Scand J Caring Sci. 2013;27:905-12.

17. Schlenk EA, Erlen JA, Dunbar-Jacob J, McDowell J, Engberg S, Sereika $\mathrm{SM}$, et al. Health-related quality of life in chronic disorders: a comparison across studies using the MOS SF-36. Qual Life Res. 1998;7:57-65.

18. Chubachi S, Nakamura H, Sasaki M, Haraguchi M, Miyazaki M, Takahashi S, et al. Polymorphism of low-density lipoprotein receptor-related protein 5 gene and emphysema severity are associated with osteoporosis in Japanese patients with or at risk for COPD. Respirology. 2015;20:286-95.

19. Makita H, Nasuhara Y, Nagai K, Ito Y, Hasegawa M, Betsuyaku T, et al. Characterisation of phenotypes based on severity of emphysema in chronic obstructive pulmonary disease. Thorax. 2007;62:932-7.
20. Yock PG, Popp RL. Noninvasive estimation of right ventricular systolic pressure by Doppler ultrasound in patients with tricuspid regurgitation. Circulation. 1984;70:657-62.

21. Clini E, Cremona G, Campana M, Scotti C, Pagani M, Bianchi L, et al. Production of endogenous nitric oxide in chronic obstructive pulmonary disease and patients with cor pulmonale. Correlates with echo-Doppler assessment. Am J Respir Crit Care Med. 2000;162:446-50.

22. Schroeder JD, McKenzie AS, Zach JA, Wilson CG, Curran-Everett D, Stinson DS, et al. Relationships between airflow obstruction and quantitative CT measurements of emphysema, air trapping, and airways in subjects with and without chronic obstructive pulmonary disease. Am J Roentgenol. 2013;201:W460-70.

23. van Manen JG, Bindels PJ, Dekker FW, Bottema BJ, van der Zee JS, Ijzermans CJ, et al. The influence of COPD on health-related quality of life independent of the influence of comorbidity. J Clin Epidemiol. 2003;56:1177-84

24. Nishimura M, Makita H, Nagai K, Konno S, Nasuhara Y, Hasegawa M, et al. Annual change in pulmonary function and clinical phenotype in chronic obstructive pulmonary disease. Am J Respir Crit Care Med. 2012;185:44-52.

25. Tanabe N, Muro S, Hirai T, Oguma T, Terada K, Marumo S, et al. Impact of exacerbations on emphysema progression in chronic obstructive pulmonary disease. Am J Respir Crit Care Med. 2011;183:1653-9.

26. Incalzi RA, Corsonello A, Pedone C, Masotti G, Rengo F, Grassi V, et al. Use of antibiotics in elderly patients with exacerbated COPD: the OLD-chronic obstructive pulmonary disease study. J Am Geriatr Soc. 2006;54:642-7.

27. Fried TR, Vaz Fragoso CA, Rabow MW. Caring for the older person with chronic obstructive pulmonary disease. JAMA. 2012;308:1254-63.

28. Blanchette CM, Berry SR, Lane SJ. Advances in chronic obstructive pulmonary disease among older adults. Curr Opin Pulm Med. 2011;17:84-9.

29. Vaz Fragoso CA, Gill TM. Respiratory impairment and the aging lung: a novel paradigm for assessing pulmonary function. J Gerontol A Biol Sci Med Sci. 2012;67:264-75.

30. Fragoso CA, Concato J, McAvay G, Yaggi HK, Van Ness PH, Gill TM. Staging the severity of chronic obstructive pulmonary disease in older persons based on spirometric Z-scores. J Am Geriatr Soc. 2011;59:1847-54.

31. Wolff JL, Starfield B, Anderson G. Prevalence, expenditures, and complications of multiple chronic conditions in the elderly. Arch Intern Med. 2002:162:2269-76.

\section{Submit your next manuscript to BioMed Central and we will help you at every step:}

- We accept pre-submission inquiries

- Our selector tool helps you to find the most relevant journal

- We provide round the clock customer support

- Convenient online submission

- Thorough peer review

- Inclusion in PubMed and all major indexing services

- Maximum visibility for your research

Submit your manuscript at www.biomedcentral.com/submit
() Biomed Central 